\title{
RENDUELES, César (2013): Sociofobia. El cambio político en la era de la utopía digital. Capitan Swing: Madrid, 206 páginas.
}

\author{
Lucía Del Moral Espín
}

"Vivimos en una jungla semiótica que premia la fragmentación y castiga las narraciones continuas y coherentes. La idealización de Internet y las comunidades digitales es su expresión ideológica más evidente" (p. 181). De esta forma desolada describe nuestro presente el ensayo Sociofobia. El cambio político en la era de la utopía digital. Su autor, Cesar Rendueles (Girona, 1975), es profesor de Sociología en la Universidad Complutense de Madrid, autor también del blog "Espejismos digitales, el cambio político en la era de la sociofobia" y editor de textos de autores clásicos, como Walter Benjamin, Karl Polanyi o Karl Marx. Sociofobia se ha convertido en solo unos meses en un fenómeno mediático y de público (va por su tercera edición). Votado como el mejor libro de ensayo de 2013 por los lectores de El País, y definido como uno de los 10 mejores libros del año por el suplemento Babelia, el texto ha dado lugar a multitud de entrevistas, comentarios y debates en blogs, redes sociales y en el entorno digital en general.

Sociofobia mete el dedo en la Ilaga, precisamente porque analiza y actualiza con una fina ironía y un aplastante sentido común uno de los dilemas éticos fundamentales de la izquierda: la construcción de relaciones sociales solidarias respetuosas con el libre desarrollo individual. Para Rendueles, el ciberfetichismo, el ciberutopismo, el mileniarismo digital, la ideología internetcentrista digital o californiana, por citar tan solo algunos términos utilizados por el propio autor, serían una mala respuesta a esta fundamental pregunta y a su versión estilizada: el dilema de los bienes comunes.

El texto se divide en cuatro apartados: Sociofobia, La utopía digital, Después del capitalismo y Coda. 1989. En el primero de ellos, Rendueles plantea que nos encontramos en un periodo en el que "el mercado inunda la totalidad de nuestras vidas con una intensidad que otros proyectos expansivos y universalistas (...) jamás se atrevieron a soñar" (p. 19); la postmodernidad ha acelerado el movimiento de destrucción de los vínculos sociales tradicionales; las relaciones personales de dependencia resultan 
sospechosas y la continuidad de las carreras laborales, de las relaciones afectivas o de las lealtades políticas parecen reliquias de otras épocas. Esto es la sociofobia, no solo vivir en un estado permanente de pánico a la densidad antropológica (p. 16) y en la aceptación del vértigo del nihilismo social, sino asumirlo como una opción deseable (deseable porque la alternativa parece ser el retorno reaccionario a sociedades tradicionales en forma de pobreza y fanatismo).

Pero el autor no acepta esta opción y, tras denunciar que las consecuencias de los dogmas de la utopía neoliberal son crisis especulativas cada vez más virulentas y destructivas, arremete, en la segunda parte del texto, contra lo que supuestamente sería el gran consenso de nuestra época: la capacidad de las tecnologías digitales para generar dinámicas sociales positivas cuando esa utopía neoliberal hace aguas. Un consenso que entiende que la solución al deterioro especulativo de los mercados es la economía del conocimiento; que la respuesta a la precarización de nuestros vínculos y nuestras vidas son las redes sociales; que la potencia de Internet y la ciberpolítica son el motor de la regeneración de la democracia y de superación de los dilemas prácticos heredados de la Modernidad. Rendueles critica ferozmente este dogma ciberfetichista. Según el autor, la ideología de la red no ha generado una realidad social aumentada, sino disminuida. "Sencillamente ha rebajado nuestras expectativas respecto a lo que cabe esperar de la intervención politica o las relaciones personales". Ante esto Sociofobia propone, en su tercera parte, una reevaluación crítica de las tradiciones políticas antagonistas para pensar el postcapitalismo. En ese sentido plantea que "el mayor desafío al ciberfetichismo y la sociofobia no es el ludismo o comunitarismo sino la concreción política" (p. 158) y ésta no se puede dar en la interacción formal inspirada en la tecnocooperación. Según el autor, el fundamento de los proyectos cibernéticos es la representación de nuestra vida en común como una mera categoría conceptual que une a individuos frágiles y fluidos a través de procedimientos técnicos aparentemente indiferentes a las identidades personales empíricas. En ese sentido, internet desempeñaría una función análoga a la del mercado de trabajo, sería un dispositivo que permitiría liberar la actividad cooperativa de las condiciones institucionales en las que tradicionalmente se habia desarrollado. Frente a esto Rendueles exclama: "Somos codependientes y cualquier concepción de la libertad personal como base de la ética tiene que ser coherente con esa realidad antropológica" (p. 143); pero va un paso más allá, invita a considerar nuestra naturaleza dependiente como un asunto político y revindica una ética del cuidado como la ideología y la práctica que deben guiar nuestra acción colectiva para conseguir un tipo de relaciones antagónicas a las del capitalismo. "La emancipación y la igualdad, la libre realización en común de nuestras capacidades, no se puede desvincular del mutuo cuidado de nuestras debilidades" (p. 152).

Con este arriesgado discurso, Rendueles levanta ampollas y esto se ha reflejado en las reseñas y críticas que se han generado en torno a este libro. De especial interés resulta el diálogo que Amador Fernández-Savater (2013) establece con el autor, planteándole cinco preguntas de las que quiero destacar tres: la primera estaría relacionada con los 
contornos de la ideología ciberfetichista: “QQuiénes son los ciberfetichistas? ¿Con quién está discutiendo César?"; realmente el autor no aporta citas concretas y tiende a ignorar que las perspectivas que critica no constituyen un bloque homogéneo, sino que podemos encontrar diferentes posiciones, conflictos y complicidades entre ellas. La segunda tiene que ver con la contraposición entre vínculos duraderos y vínculos débiles. "Está muy bien no confundirlas, pero ¿por qué oponerlos?". Cualquier proyecto requiere de un núcleo duro con relaciones densas y permanentes y compromisos fuertes y estables, pero también se beneficia de aportaciones puntuales y colaboraciones ocasionales. La tercera pregunta versa sobre el término mismo de "sociofobia" y la reivindicación perversa por parte de las posturas más reaccionarias de la importancia de los vínculos sociales fuertes. Me extenderé algo más sobre este punto. Precisamente, aunque la idea de la Big Society parecía haber desaparecido de la primera línea del discurso político, el premier británico David Cameron volvió a reivindicar su espíritu en su último discurso navideño. Desde 2010 el Gobierno de la coalición liberal-conservador en el Reino Unido viene impulsando, por un lado, el mayor paquete de recortes en servicios públicos y prestaciones visto en décadas y, por otro, la Big Society, un programa político, social y cultural de cambios para transformar el modo en el que se prestan los servicios públicos, supuestamente mediante el empoderamiento de las comunidades, la redistribución del poder del Estado a los ciudadanos y la promoción de una cultura del voluntariado como forma de reparar la 'quebrada' y 'atomizada' sociedad británica. De hecho, cuando Cameron planteó la idea de Big Society, ésta parecía un ejercicio de branding para distanciar el partido del Thatcherismo y, en particular, de la retórica libertaria de 'la sociedad no existe' (Kisby, 2010: 483).

Por lo tanto, y frente a la posible apropiación reaccionaria de este tipo de discursos, conviene no olvidar que un vínculo denso y permanente puede estar hecho de desigualdades y opresiones. Y en este sentido me llama la atención la ausencia, en el texto de Rendueles, de una mención expresa de los movimientos feministas y de las sociólogas y economistas feministas que tanto han hecho por sacar a la luz y reivindicar la importancia de los cuidados y la universalidad de la dependencia y que en los últimos tiempos vienen reflexionando sobre 'el tipo de vida que merece la pena ser vivida'. ¿Cómo pensar estos asuntos sin los trabajos, ya clásicos, de Teresa Torns, Cristina Carrasco o Amaia Pérez Orozco o colectivos como Precarias a la Deriva, por citar tan solo algunos ejemplos? En cierta medida pienso que esta ausencia es lo que permite al autor - y aquí apunto otro posible eje de crítica - una idealización de ese espacio fundamental de provisión del cuidado en nuestras sociedades: las familias. Es innegable que las relaciones familiares no se rigen por la racionalidad instrumental (¿es que algún tipo de relación realmente se rige por ella?), pero no por ello han de reivindicarse acríticamente. Desde hace décadas, las perspectivas feministas vienen cuestionando la naturaleza sosegada y armónica de los hogares y denunciando la violencia, opresión y desempoderamiento económico y político para mujeres y niños/as que se produce en ellos. No olvidemos que, como bien subraya Sandra Harding, es en los hogares "donde el patriarcado está en casa" (Harding, 2008: 226). Rendueles reivindica una cooperación 
dependiente del compromiso, entendido como norma social, frente a la dependiente del altruismo, entendido como elección personal, que se daría en el contexto digital. Ahora bien, si en los hogares existe esta norma social habrá que preguntarse de dónde surge esta norma y qué consecuencias tiene sobre sus diferentes miembros. Una aproximación a estos asuntos que no incluya las perspectivas feministas, sin duda, será insuficiente. Por desgracia, ésta no siempre está presente en el texto de Rendueles, que por ejemplo plantea que "el neosexismo es, sobre todo, el subproducto del consumismo" (p. 178). Sinceramente creo que en un periodo de ataque tan brutal a los derechos de las mujeres cuestionar la realidad del "proceso de retroceso en las dinámicas igualitarias" y la "existencia de un contraataque neosexista", resulta, cuanto menos, irresponsable. Sin embargo no dudo de que Rendueles sea consciente de la necesidad de replantear y construir nuevos modelos de crianza y de provisión de cuidados más allá del espacio doméstico tradicional. De manera consciente o inconsciente Sociofobia complementa otro de los libros que más han dado que hablar en el último año, Dónde está mi tribu, ensayo que analiza los procesos de crianza - y, se podría decir, que los de cuidados en general - abogando, precisamente, por un marco más amplio que el de la familia o el de la pareja madre-hijo. Su autora, Carolina del Olmo, directora de Cultura en el Círculo de Bella Artes y de la revista Minerva, en los agradecimientos, menciona expresamente el apoyo y contribución de Oscar Rendueles al desarrollo del libro.

Por otro lado, resulta interesante comentar Sociofobia desde la experiencia del Grupo Interdisciplinario de Estudios y Comunicación Cultura y Cambio Social, COMPOLÍTICAS, que en el último año ha publicado títulos como Ciudadanía, Tecnología y Cultura: Nodos conceptuales para pensar la nueva mediación digital (Gedisa). El objetivo de este grupo es la producción de un pensamiento crítico sobre la comunicación y la cultura digital más allá de las lógicas dicotómicas que hace una década modelaban buena parte del debate teórico y académico. En este sentido, este grupo trabaja para promover un desarrollo social de las TIC ajustado a los procesos de apropiación social por la comunidad, a las necesidades radicales de expresión y desarrollo cultural de los sujetos y a los retos político-económicos de interés y dominio público (Sierra Caballero, 2013: 26). Con ello, COMPOLíTICAS plantea una visión crítica que, en cierta medida, se aparta tanto del ciberutopismo que critica Rendueles como de la distopía cibérnetica que presenta este autor.

En cualquier caso, quiero subrayar que, a pesar de su desgarrada descripción del presente, Rendueles entreabre una vía de fuga al plantear que las sociedades actuales disponen de los mimbres necesarios para afrontar la democratización, la igualdad, la libertad y la solidaridad (p. 36). De hecho, en sus últimas líneas, invita a pensar el postcapitalismo como un proyecto "factible, cercano y amigable" y da un paso más allá, indicando el camino a seguir, al subrayar que "la codependencia no tutelada es la materia prima con la que podemos diseñar un entorno institucional amigable e igualitarista" (p. 152). En definitiva, se comparta o no su visión de la ideología de la red como obstáculo para avanzar hacia este tipo de entornos, la lectura apasionante de Sociofobia nos obliga a repensar críticamente algunos términos fundamentales de nuestro tiempo, como los de cooperación, compromiso, 
RECENSIONES

comunidad y participación, y nos recuerda hasta qué punto somos personas sólo parcialmente racionales, frágiles y universalmente codependientes. 